\title{
Knowledge Building in robotics for STEM education
}

\author{
Ahmad Khanlari \\ University of Toronto \\ a.khanlari@mail.utoronto.ca
}

\begin{abstract}
Robotics, with its multidisciplinary nature, has been considered as a great tool for teaching and learning Science, Technology, Engineering, and Mathematics (STEM) subjects. However, educational robotics often goes on a competitive way which may diminish its potentials. The purpose of this study is to take another approach to use robotics for teaching STEM subjects, which might be more effective than competition based learning.
\end{abstract}

Keywords: Knowledge Building, Robotics, Mathematics, STEM education.

\section{Introduction}

Along with robotics technology development, researchers and educators have employed robots to support education (Han, 2012). Several studies (e.g. Attard, 2012) have shown that hands-on robotics is engaging, creates constructive learning environments for a better understanding of STEM disciplines, and attracts students towards STEM subjects. It has been claimed in some studies (e.g. Giannakopoulos, 2009) that Competition Based Learning (CBL) is the most effective way to integrate robotics into subjects such as math and physics. In CBL, students form small groups, collaborate within their groups, and build and program their robots in order to accomplish challenges, beat others and get credit (Kanda, Shimada, \& Koizumi, 2012). Although the concept of competition in education is supported by several studies (e.g. Lawrence, 2004), there are several concerns in regards to competitions in education. One concern is that competitions usually focus on winning, while education should focus on processes that ultimately result in success (Murphy, 2000). Therefore, competitions may have negative effects on the learning process, and force students to focus on a limited set of "winning" goals rather than a process more attuned to deep understanding (Vockell, 2004). For instance, Hallak, Armoni, and Ben-Ari (2015) stated that sometimes learning opportunities were sacrificed by students in favor of building robots to accomplish the challenges. Another concern is that during competitive activities, communication and helping others is usually minimized because students usually perceive their goals as only being reached if other students fail to achieve their goals (Johnson, Johnson, \& Smith, 1991). In fact, the growing emphasis on the final products of competitive activities sometimes leads students to disregard other goals such as groups' interactions, collaboration and shared vision (Cohen, Brody, \& SaponShevin, 2004). Therefore, competitions may "discourage active construction of knowledge and the development of talent by isolating students" (Johnson et al., 1991, p. 11). Such a learning environment creates a dichotomy in which talented students are the winners at the expense of less talented students. In robotics competitions, like other competitive activities, it is very common to have some really developed projects and some projects in their early stages of development. For example, Hallak and colleagues (2015) stated that only a few groups of their students who were learning robotics in a CBL approach could successfully complete their robots to accomplish the challenges. One potential solution for these challenges and concerns is to teach robotics employing collaborative approaches. Although small-scale collaboration has the potential to mitigate the negative effects of robotics competitions, it has its drawbacks as well. For example, the results of a study showed that several teams could not complete the robotics projects, and the average completion rate was 68\% (Karahoca, Karahoca, \& Uzunboyluhave, 2011). In fact, information in small groups is not readily available to the full group, thus less likely to spread and be built on (Scardamalia, 2002). Engaging students in a largescale collaboration, in which students collaborate with all other students, may result in fewer students at the periphery. This study aims to create a united knowledge community where students take collective responsibility for advancing knowledge in robotics and science, and build robots of good quality that reflect knowledge advances. Knowledge Building theory, pedagogy and technology has the potential to create such a community in which innovations and knowledge are democratized for the benefit of all.

\section{Knowledge Building Pedagogy, Theory, and Technology}

Scardamalia (2002) and Scardamalia and Bereiter (2006) presented 12 principles that altogether describe 
Knowledge Building as a principle-based pedagogy and that are set forth to make knowledge creation more accessible to teachers and students. These 12 principles frame Knowledge Building as an idea-centered pedagogy with students as epistemic agents, creating knowledge through engaging in complex socio-cognitive interactions. Knowledge Building turns high level agency to students and assumes that students should set their learning goals, engage in planning, and monitor and assess their work and idea coherence. Knowledge Building, with its 12 principles, has the potential to "set a knowledge building classroom off as profoundly different from even the best of traditional and modern classrooms" (Scardamalia, 2002, p. 77).

Knowledge Building places great emphasis on the notion of community and collective responsibility for knowledge advancement. In such a community, students are encouraged to advance community knowledge through participation in progressive discourse (Beretier, 1994; Bereiter \& Scardamalia, 1993) and contribute to the community knowledge and a shared knowledge objective (Bereiter, Scardamalia, Cassells, \& Hewitt, 1997). In essence, in Knowledge Building, knowledge is viewed as a social product with students taking collective responsibility for the state of public knowledge and continual idea improvement (Bereiter, 2002; Scardamalia, 2002; Scardamalia \& Bereiter, 2006). From a Knowledge Building perspective, the community succeeds through distribution of group effort across all members, not the concentration of efforts amongst a few individuals. Therefore, beyond ideas held privately by individuals, they should be made available to the community as publicly accessible artifacts that can be discussed, interconnected, revised, and superseded (Scardamalia \& Bereiter, 2003). In fact, individual interests and expertise are complemented by those of the community as each individual tries to achieve both individual and community goals (Amar, 2002).

\section{Methodology}

As the study will integrate three complex models and systems of interactivity as well as a broad base of analytic tools, the research will take continual design iterations. Therefore, a Design-Based Research (DBR) methodology (Brown, 1992; Collins, 1992) will be employed. DBR supports the iterative design and improvement of the technology elements and curriculum materials such as analytic tools and activities. It also contributes to the testing of the underlying Knowledge Networks. DBR, by its commitment to the development of sustained innovations in education, is distinguished from other types of educational research (Bereiter, 2002b). The goals of DBR are emergent, guided by a "vision of as-yetunrealized possibilities" (Bereiter, 2002b, p. 326) that arise and evolve over each design cycle. DBR researchers not only seek to examine the usability or feasibility of new educational technologies, but also aim to understand how these technologies can be productively embedded into educational systems (Bell, Hoadley, \& Linn, 2004) as well as the relative improvability of these designs within such systems (Bereiter, 2002b). Collins (1992) claimed that topics like robotics and artificial intelligence are design sciences, where we need to investigate how different learning-environment designs affect dependent variables in teaching and learning, and how designed artifacts such as robots behave under different conditions. Therefore, DBR is well suited for this study.

\section{Method}

The participants of this work in progress study include a grade 5 classroom (14 students), where students explore math units using robotics. At the beginning of each session, students form a Knowledge Building circle, and involve in a whole class discussion to share their plan to solve the challenge. Then, they form their groups and do their handson robotics activities. At the end of the session, they form another Knowledge Building circle to share their experience with the whole community, and learn from each others' experiences. They also continue their discussion in an online learning environment, called Knowledge Forum (ß- a web-based discourse medium specifically designed to support production and refinement of community knowledge to advance understanding of the world and effective action through social interaction. Knowledge Forum with its specific design provides opportunities for students to act as knowledge workers in an open space (Scardamalia, 2004).

In this study, students explored math units trough robotics. They math units that are covered include variables, data management, shapes, and measurements.

\subsection{Data analysis}

While many studies within the context of Knowledge Building have only focused on students' online discourses posted in Knowledge Forum, in this study I examine both online and face-to-face discourses, in order to analyze the full learning discourses. The face-to-face discourse is usually called Knowledge Building talk (Scardamalia \& Bereiter, 2006b) and engages students in "metadiscourse." Metadiscourse, which is defined as discourse about discourse (Goldman \& Scardamalia, 2013), allows students to collectively review and discuss the conceptual landscape generated through online discourse, monitor problems and goals, report and reflect on achievements, and redefine goals and collaborative actions (Zhang, Scardamalia, Reeve, \& Messina, 2007). While online discourses are collected through Knowledge Forum, I attended classes to observe and record students' face-to-face discourses and take fieldnotes. The face to face discourse that students had 
were recorded, transcribed, and analyzed. Also, the notes posted by students in Knowledge Forum are collected and a discourse analysis method is employed to analyze students understanding of robotics and mathematics.

In this part, Latent semantic analysis (LSA) and Discourse analysis will be employed to address the following questions:

- How and if Knowledge Building approach may result in a better learning experience in which all groups design high quality robots?

- How and if innovative ideas rippled through collaborative networks?

- How and if students' ideas improved as a result of the spread of innovative ideas?

\section{Preliminary results}

The preliminary results of the analysis of the fieldnotes show that employing Knowledge Building pedagogy provided a learning environment that students take responsibility to help their peers to improve their ideas and robotics designs. For example, when a group of students was struggling with fixing a problem that prevented the robot to move, another group helped them to fix the issue and informed them the way they can fix the gears to make the robot move. Also, the preliminary results of analyzing students notes revealed that the knowledge building culture, which is the culture of support and respect, created a learning environments that students share their knowledge with others and help each other to improve their ideas. for example, students helped each other to learn more about robotics (e.g. sensors, movements) learn more about

\section{REFERENCES}

Amar, A. D. (2002). Managing knowledge workers: Unleashing innovation and productivity. Westport, CT: Quorum Books.

Attard, C. (2012). Teaching with technology: Exploring the use of robotics to teach mathematics. Australian Primary Mathematics Classroom, 17(2), 31-32.

Bell, P., Hoadley, C. M., \& Linn, M. C. (2004). Rationale for design-based research in education. In M. C. Linn, E. A. Davis, \& P. Bell (Eds.), Internet environments for science education (pp.73-85). Mahwah, NJ: Lawrence Erlbaum Associates Inc.

Bereiter, C. (1994). Implications of postmodernism for science, or, science as progressive discourse. Educational Psychologist, 29(1), 3-12.

Bereiter, C. (2002b). Design research for sustained innovation. Japanese Cognitive Science Society, 9(3), 321-327. mathematics (e.g. data management, variables, measurements), better understand science topics (e.g. speed). In fact, the Knowledge Building approach created a supportive environment in which no group is left alone and all groups have the opportunity to create and design good quality that reflect knowledge advances.

\section{Conclusion}

Although few students may grow up to be roboticists, all students in modern societies will have their lives affected by robotics. Learning about it is important, as is acquiring hands-on experience with it. But compartmentalized learning is not enough. It is important to have a community in which there are not insiders and outsiders but one where everyone can move between roles of doer, explainer, and critic. That is why this work in progress research, which treats robotics within the context of a collaborative knowledge-building community, offers both a wider perspective and a deeper approach to this 21 st century phenomenon.

\section{Future directions}

For the next step, I am going to analyze all the gathered data, including online discourses and face to face discourse, in order to carefully examine how using robotics as the focal activity and Knowledge Building theory and pedagogy as the educational framework can help students to effectively learn STEM-related subjects. Also, addressing other research questions, mentioned in section 4.1 is another goal of the future directions.

Bereiter, C. (2002a). Education and mind in the knowledge age. Mahwah, NJ: Erlbaum.

Bereiter, C., \& Scardamalia, M. (1993). Surpassing ourselves: an inquiry into the nature and implications of expertise. Chicago: Open Court.

Bereiter, C., Scardamalia, M., Cassells, C., \& Hewitt, J. (1997). Postmodernism, knowledge building, and elementary science. The Elementary School Journal, 97(4), 329.

Brown, A. L. (1992). Design experiments: Theoretical and methodological challenges in creating complex interventions in classroom settings. Journal of the Learning Sciences, 2(2), 141-178.

Cohen, E.G., Brody, C., \& Sapon-Shevin, M. (Eds.) (2004). Teaching cooperative learning: The challenge for teacher education. Albany, NY: Suny Press. 
Collins, A. (1992). Toward a design science of education. In E. Scanlon, \& T. O'Shea (Eds.), New directions in educational technology (pp. 15-22). Berlin: Springer-Verlag.

Giannakopoulos, N. (2009, September). Experiences from WRO 2009 competition and verifications about the robotics incorporation in the school. Paper presented at the Lessons Learnt from the TERECoP Project and New Pathways into Educational Robotics across Europe, Athens, Greece.

Goldman, S. R., \& Scardamalia, M. (2013). Managing, understanding, applying, and creating knowledge in the information age: Nextgeneration challenges and opportunities. Cognition and Instruction, 31(2), 255-269.

Hallak, F., Armoni, M., \& Ben-Ari, M. (2015). The effectiveness of robotics competitions on students' learning of computer science. Olympiads in Informatics, 9, 89-112.

Han, J. (2012). Emerging technologies: Robot assisted language learning. Language Learning \& Technology, 16(3), 1-9.

Johnson, D., Johnson, R., \& Smith, K. (1991). Active learning: Cooperation in the college classroom. Edina, MN: Interaction.

Kanda, T., Shimada, M., \& Koizumi, S. (2012). Children learning with a social robot. In the Proceedings of the $7^{\text {th }}$ annual ACM/IEEE International Conference on Human-Robot Interaction (pp. 351-358). ACM, New York: NY.

Karahoca, D., Karahoca, A., \& Uzunboylu, H. (2011). Robotics teaching in primary school educationby project based learning for supporting science and technology courses. Procedia Computer Science, 3, 1425-1431.
Murphy, R. R. (2000).Using robot competitions to promote intellectual development. AI Magazine, 21(1), 77-90.

Scardamalia, M. (2002). Collective cognitive responsibility for the advancement of knowledge. In B. Smith (Ed.), Liberal education in a knowledge society (pp. 67-98). Chicago, IL: Open Court.

Scardamalia, M. (2004). CSILE/Knowledge Forum. In A. Kovalchick, \& K. Dawson (Eds.), Education and technology: an encyclopedia (pp. 183-192). Santa Barbara, CA: ABC-CLIO.

Scardamalia, M., \& Bereiter, C. (2003). Knowledge Building. In Encyclopedia of education (13701373). New York: Macmillan Reference, USA.

Scardamalia, M., \& Bereiter, C. (2006). Knowledge building: Theory, pedagogy, and technology. In R. K. Sawyer (Ed.), The Cambridge handbook of the learning sciences (pp. 97-115). Cambridge University Press.

Scardamalia, M., \& Bereiter, C. (2006b). FCL and Knowledge Building: A continuing dialogue. Retrieved from http://www.ikit.org/fulltext/AnnBrownOct10.06 .pdf.

Vockell, E. (2004). Educational psychology: A practical approach. Purdue University.

Zhang, J. W., Scardamalia, M., Lamon, M., Messina, R., \& Reeve, R. (2007). Socio-cognitive dynamics of knowledge building in 9- and 10year-olds. Educational Technology Research and Development, 55, 117-145. 